\title{
A INTERTEXTUALIDADE NA \\ CONSTRUÇÃO ARGUMENTATIVA \\ MIDIÁTICA DO GOLPE DE 2016: UMA \\ ANÁLISE DE DISCURSO CRÍTICA NA \\ REVISTA VEJA
}

Antonio Edson Alves da Silva1

\begin{abstract}
Resumo: Este artigo analisa as estratégias de uso da linguagem na forma de construção de sentido acerca do processo de impedimento da presidenta Dilma Rousseff, em 2016. Sendo assim, o objetivo geral é analisar os recursos intertextuais que constituíram o discurso midiático de legitimação do Golpe de 2016, na revista Veja tendo em vista o significado acional, com as ocorrências de intertextualidade. Para tanto, toma-se como referencial teórico principal, a Análise de Discurso Crítica (ADC), de Norman Fairclough (2001; 2003). O corpus selecionado é constituído de um artigo de opinião circulado pela grande mídia hegemônica. Ao fim, as principais reflexões apontam-se para o entendimento de que a mídia brasileira contribuiu efetivamente para a legitimação do Golpe de 2016, tendo em vista as ideologias políticas da direita e o pensamento das grandes corporações que orientaram sua postura condenatória acerca dos governos petistas.
\end{abstract}

Palavras-Chave: Discurso. Mídia. Golpe de 2016.

\section{THE INTERTEXTUALITY IN THE MEDIA'S ARGUMENTATIVE CONSTRUCTION OF THE 2016 COUP: A CRITICAL DISCOURSE ANALYSIS IN THE MAGAZINE VEJA}

\begin{abstract}
This article analyzes language use strategies in the form of building meaning about the process of impeachment of President Dilma Rousseff in 2016. Thus, the general objective is to analyze the intertextual resources that constituted the media discourse of legitimization of the Coup of 2016, in the magazine Veja in view of the acional meaning, with the occurrences of intertextuality. For this purpose, Norman Fairclough's Critical Discourse Analysis (ADC) $(2001 ; 2003)$ is taken as the main theoretical reference. The selected corpus consists of an opinion article circulated by the great hegemonic media. At the end, the main reflections point to the understanding that the Brazilian media effectively contributed to the legitimization of the 2016 Coup, given the political ideologies of the right and the thinking of the large corporations that guided their condemnatory stance on the petitioner governments.
\end{abstract}

Keywords: Discourse. Media. 2016 coup.

1 Doutorando em Linguística Aplicada pelo Programa de Pós-Graduação em Linguística Aplicada da Universidade Estadual do Ceará (PosLA-UECE). E-mail edson.crat@gmail.com 


\section{INTRODUÇÃO}

Desde o primeiro mandato, a presidenta Dilma Rousseff (2011-2014) passou por crises internas e externas que impediram a solidificação de sua proposta de governo, mesmo tendo uma base parlamentar aliada maior do que seu antecessor, na Câmara Federal. Para Guerra (2017), os problemas internos, como alianças políticas, crises e rechaças no governo, bem como a falta de aceitação da população, posteriormente, com base na opinião formada pela grande mídia, foram fazendo com que seus aliados se distanciassem cada vez mais e assumissem novos rumos, em oposição à postura da então presidenta, alegando que não cedia às vontades dos partidos coligados.

Nesse cenário conflituoso, no dia 02 de dezembro de 2015, o presidente da Câmara dos Deputados, Eduardo Cunha, aceitou a abertura do processo de impedimento da presidenta eleita, com base em denúncias por supostos crimes de responsabilidade, apresentadas pelo procurador de Justiça aposentado Hélio Bicudo e pelos advogados Miguel Reale Junior e Janaina Paschoal.

Este artigo é parte da pesquisa de mestrado desenvolvida no Programa de Pós-Graduação em Linguística Aplicada, na Universidade Estadual do Ceará, e dialoga com teóricos das mais diversas áreas, como ciências da comunicação, ciências linguísticas, ciências sociais, ciências políticas, ciências econômicas, ciências históricas e ciências jurídicas que compreendem o processo de impedimento da presidenta Dilma Rousseff como sendo um golpe parlamentar, jurídico e midiático contra a população brasileira.

Para tanto, a relevância deve-se ao fato de que ele traz uma discussão sobre um importante acontecimento que impactou e vem ainda impactando negativamente os rumos do país e que precisa ser melhor compreendido pela população. Como diz Jessé Souza, os golpes ainda acontecem facilmente porque a população nunca entende direito por que eles acontecem.

Neste trabalho, que possui natureza qualitativa e interpretativista, utilizamos como corpus dois artigos de opinião intitulados Impeachment não é guerra e Impeachment põe fim ao ciclo do PT no poder, publicados na revista $V e j a$ no período que perdurou o processo de impedimento da presidenta Dilma, tendo em vista o ranking apresentado pela Associação Nacional dos Editores de Revista (ANER), colocando-a como sendo o folhetim semanal de maior circulação, divulgação e consumo, por parte dos leitores brasileiros, informação ratificada, posteriormente, pelo Ministério das Comunicações.

Nesse sentido, tomando como referência o modelo de Análise de Discurso Crítica (ADC) proposto por Fairclough $(2001 ; 2003)$, este trabalho tenta dar conta das formas pelas quais essa revista produziu um discurso de legitimação do Golpe de 2016, ou seja, dos recursos linguísticos mobilizados nas práticas discursivas em questão para produzir tal legitimação. Em termos mais específicos este trabalho analisa como as práticas discursivas em questão produziram um discurso de legitimação do Golpe de 2016 nos seus modos de ação, analisados através dos recursos de intertextualidade.

\section{ANÁLISE DE DISCURSO CRÍTICA}

Entendemos aqui como os recursos de intertextualidade foram conferidos aos textos jornalísticos de grande circulação brasileira no que denominamos Golpe de 2016. Para dar conta disso, fizemos uma análise minuciosa de dois artigos de opinião publicados pela grande mídia hegemônica brasileira, tendo por base a contribuição das teorias que serão apresentadas, para compreender tais fenômenos sociais.

Nesse sentido, a Análise de Discurso Crítica tem contribuído muito fortemente para 
uma variedade de abordagens nos mais diversos grupos disciplinares, em virtude do seu caráter profundo de análise textual orientada, visando suas implicaturas nas estruturas e práticas sociais. Para um trabalho analítico mais eficaz, faz-se necessário compreender as relações de poder e ideologia que envolvem os mais diversos contextos trabalhados, numa abordagem crítica da linguagem conforme destaca Fairclough (2001. p. 31),

\begin{abstract}
As abordagens críticas diferem das nãocríticas não apenas na descrição das práticas discursivas, mas também ao mostrarmos como o discurso é moldado por relações de poder e ideologia e os efeitos construtivos que o discurso exerce sobre as identidades sociais, as relações sociais e os sistemas de conhecimento e crença (FARICLOUGH, 2001, p. 31).
\end{abstract}

Toda abordagem crítica da ADC é impulsionada, segundo Fairclough, pela Linguística Crítica, nascida na década de 1970, com base nos estudos de Fowler, Kress e Hodg, na Universidade de East Anglia. Os teóricos buscavam unificar um método de análise de texto com as teorias sociais do funcionamento da linguagem, recorrendo à compreensão dos processos políticos e ideológicos que estão intrinsecamente ligados à política e à ideologia.

De igual modo, van Dijk (2017) também compreende a ADC como um tipo de investigação sistemática que estuda preponderantemente as relações de (abuso de) poder, a dominação e as mais diversas manifestações de desigualdades sociais representadas, produzidas e divulgadas através de textos orais e escritas em determinados contextos sociais. "Com essa investigação de natureza tão dissidente, os analistas críticos do discurso adotam um posicionamento explicito e, assim, objetivam compreender, desvelar e, em alguma instância, opor-se à desigualdade social. (VAN DIJK, 2017, p. 113). Portanto, os analistas são entendidos como atores sociais engajados nesse processo de transformação e mudança social.
O interesse em estudar a linguagem através do discurso foi amplamente divulgado e trabalhado a partir da década de 1970, iniciado no Reino Unido, com o apoio da nascente Linguística Crítica, tendo influências positivas das mais diversas áreas do conhecimento, como a sociolinguística, a psicologia, as ciências sociais, dentre outras.

A Análise de Discurso Crítica não é, na verdade uma diretriz, uma escola, nem uma especialização semelhante a tantas outras "abordagens" nos estudos discursivos. Antes, a ADC objetiva oferecer um "modo" ou uma "perspectiva" diferente de teorização, análise e aplicação ao longo de todos os campos. Podemos encontrar uma perspectiva mais ou menos crítica em diversas áreas, tais como a pragmática, a análise da conversação, análise da narrativa, a retórica, a estilística, a sociolinguística, a etnografia, a análise da mídia, entre outras (VAN DIJK, 2017, p. 114).

Nesse sentido, percebemos uma necessidade de uma consciência explicita do papel do analista do discurso crítico, frente aos mais diversos contextos sociais de exploração, dando assim sua contribuição a essa tradição que rejeita a possibilidade de uma ciência acrítica e acomodada, mas compreende que a ciências discursivas são partes inerentes às estruturas sociais. Ademais, a relação entre sujeito, discurso e sociedade é tão tênue que o papel do analista é sempre colocado em pauta, tendo em vista seu posicionamento transgressor ao fazer uma ciência crítica engajada e comprometida com a transformação social através da consciência dos discursos hegemônicos e contra hegemônicos.

Portanto, a ADC torna-se uma abordagem interdisciplinar que estuda estratégias de como se opor aos discursos das classes dominantes, que têm uma pequena parcela, a elite, como detentora dos meios de comunicação e das práticas discursivas que permeiam todas as esferas da sociedade. Assim, é inevitável não entender os analistas críticos como normalmente militantes sociais de direitos humanos, sindicalistas e intelectuais que lutam com as palavras, como forma de contraposição das mais 
terríveis situações de opressão par parte da classe dominante.

Nessa perspectiva de investigação do significado acional, identificamos os recursos de intertextualidade no corpus, tendo em vista que esta categoria foi bastante fértil e complexa, por mostrar uma conexão semiótica entre texto, contexto e ditos anteriores que sustentam o discurso atual. De acordo com Fairclough (2001, p. 133), a intertextualidade foi cunhada por Kristeva no fim dos anos 1960, mas foi em Bakhtin que teve seu trabalho bem mais sistematizado e elaborado, entendendo as relações dialógicas que permeiam tais recursos linguísticos.

Ainda em Fairclough (2001, p. 114), percebemos a intertextualidade como a "propriedade que têm os textos de serem cheios de fragmentos de outros". Para o autor, esse elemento discursivo refere-se ao modo como uns textos podem transformar outros anteriores e reestruturar convenções existentes para a produção de novos. Essa é, segundo a ADC, uma categoria de análise potencial para trabalhar com os diversos gêneros, já que comumente os "gêneros específicos articulam vozes de maneiras específicas" (RAMALHO; RESENDE, 2011, p. 133).

Fairclough (2003) afirma que a intertextualidade é uma categoria inerentemente seletiva, principalmente em relação as vozes que serão ou não incluídas nos textos e ao modo como essas serão representadas. A seleção de quais vozes constituirão o texto e como elas serão articuladas fazem parte de um conjunto de escolhas ideológicas por parte daqueles que produzem e utilizam o gênero discursivo como forma de ação social.

A análise do modo que se constitui a articulação de vozes específicas em gêneros contribui para investigar práticas discursivas na sociedade que estão relacionadas às lutas hegemônicas (FAIRCLOUGH, 2001). A esse respeito, Resende e Ramalho (2017, p. 133) explicam que "a ausência ou a presença de vozes provenientes de textos diversos, assim como a natureza da articulação dessas 'vozes particulares', permitem explorar práticas discursivas existentes na sociedade e a relação entre elas".

Nesse sentido, Fairclough (2001) compreende a relação estreita entre intertextualidade e hegemonia, tendo em vista que o conceito intertextual direciona uma produtividade de textos, podendo transformar os anteriores e estabelecer novas relações hegemônicas, em vista a reestruturação e reorganização desses novos, oriundos de ditos previamente selecionados.

Contudo, a intertextualidade é definida de forma mais ampla, quanto Fairclough classifica os tipos de intertextualidade que podem ser identificados nos trabalhos de análise de discurso, como relato direto, trazendo marcas de citação e palavras literalmente utilizadas por outros anteriormente; vemos também o relato indireto que não apresenta marcas de citação idênticas ao texto anterior, mas são vislumbradas a partir de outras palavras, sem mudar a ideia central do emissor. Por fim, o relato indireto livre que é colocado com um intermediário entre o discurso direto e o indireto.

\section{ANÁLISE DE DADOS}

Retomando o objetivo central deste trabalho que é analisar os recursos que constituíram o discurso midiático de legitimação do Golpe de 2016, na revista Veja através do significado acional, com a ocorrência da categoria intertextualidade, em diálogo multidisciplinar com o pensamento de Jessé de Souza e das ciências sociais, entendendo que o processo de constituição do Golpe de 2016 está fincado no pensar do próprio capitalismo que vivenciamos em nossa sociedade, uma vez que, conforme Souza (2016), há no Brasil uma elite que detém o poder financeiro e que tem total força para desenhar os rumos que o país deve 
tomar, tendo em vista a necessidade de aumentar sua riqueza e explorar cada vez mais a classe trabalhadora. Na contramão dessa concepção, depois de anos em que o país era gerenciado pelas grandes corporações, em 2003, a população cansada da exploração sistemática, elege um governo oriundo da classe trabalhadora, ou seja, um metalúrgico, semianalfabeto e nordestino. Essa caracterização, atribuída ao ex-presidente Lula, tem raízes profundas no próprio preconceito das elites dominantes.

Retomando a discussão quanto ao significado acional, mostraremos aqui a análise da categoria de intertextualidade identificada no corpus, tendo em vista que esta mostrou-se bastante produtiva, por ser profícua e complexa, proporcionando diversas conexões entre texto, contexto e textos anteriores que sustentam, orientam e modifica o dito atual. Portanto, de acordo com o pensamento de Fairclough (2001, p. 133), entendemos que a intertextualidade foi desenvolvida por Kristeva no final dos anos 1960, mas Bakhtin foi quem teve o trabalho de torná-la mais sistematizada e elaborada, entendendo as relações dialógicas que permeiam esses recursos linguísticos.

Em sintonia com o pensamento dialético-relacional da ADC, entendemos que a intertextualidade é a "propriedade que têm os textos de serem cheios de fragmentos de outros". Assim, esse elemento discursivo refere-se ao modo como uns textos podem transformar outros anteriores e reestruturar convenções existentes para a produção de novos textos. Portanto, segundo a ADC, essa é uma categoria de análise em potencial para trabalhar com os diversos gêneros textuais, já que comumente esses gêneros são articulados a vozes específicas.
Nessa mesma linha de raciocínio, percebemos que a intertextualidade é uma categoria produtiva e seletiva, principalmente em relação as vozes que serão ou não incluídas no processamento de novos textos, bem como o modo como essas vozes também serão representadas. A seleção de quais vozes constituirão o texto e como elas serão articuladas fazem parte de um conjunto de escolhas ideológicas por parte daqueles que produzem e utilizam o gênero discursivo como forma de ação social.

Em suma, essa categoria é definida de forma mais ampla e aprofundada, quando Fairclough classifica os tipos de intertextualidade que podem ser identificados nos trabalhos de ADC, tais como relato direto, que mostra as marcas de citação e palavras literalmente utilizadas por outros anteriormente; o relato indireto que não apresenta marcas de citação idênticas ao texto anterior, mas são vislumbradas a partir de outras palavras, sem mudar a ideia central do emissor; e por último, o relato indireto livre que é colocado como um intermediário entre o discurso direto e o indireto.

De início, analisamos o artigo de opinião Impeachment não éguerra, de Daniel Pereira, publicado na revista $V$ eja, edição 2455 , de 04 de dezembro de 2015, logo após aceitação do pedido de impeachment pelo presidente da Câmara Federal Eduardo Cunha, em 02 de dezembro do mesmo ano. Apoiando-se no recurso multimodal da imagem da então presidenta com semblante sério e preocupado, diante dos acontecimentos que efervesciam aquele momento, Pereira (2015) apresenta fortes argumentos para formar a opinião pública quanto ao início de um processo doloroso, porém, em sua concepção, necessário para o bem do país. 


\section{Figura 1 - Imagem da presidenta Dilma Rousseff na Veja}

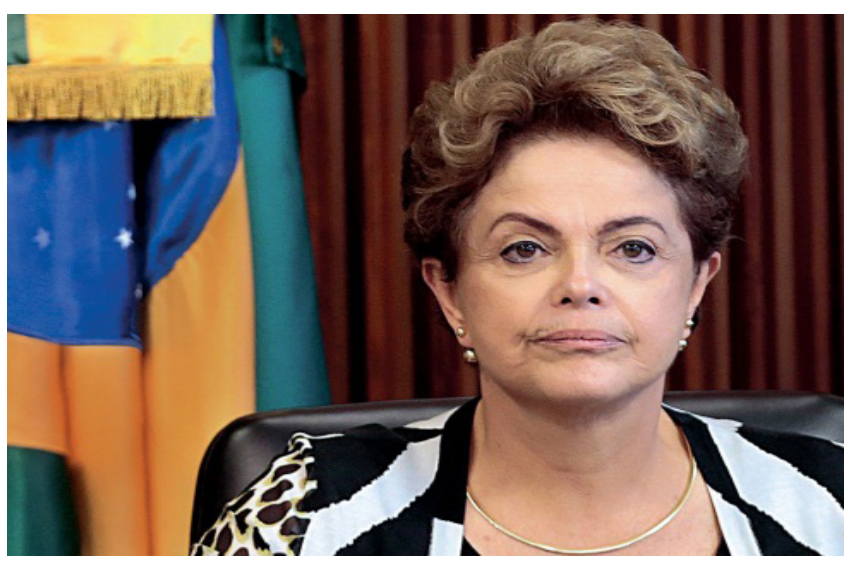

Fonte: veja.abril.com.br

O autor organiza seu texto nos moldes do artigo de opinião, apresentando seu posicionamento, como o da própria revista Veja, favorável ao desenvolvimento do processo de impedimento da então presidenta Dilma, com a perspectiva de persuasão do seu interlocutor, mostrando fatos e argumentos importantes, no sentido de dar maior credibilidade a sua escrita.

No tratamento com os argumentos para convencer seu leitor, o autor utiliza-se de muitas fontes, apresentando excessivos exemplos de intertextualidade, porém, organizado de forma descontextualizada, sem evidenciar o direito de divergir ou questionar a ideia positiva do processo de impeachment.

Pereira (2015) inicia seu texto apresentando o cenário político que o país vivenciava naquele momento, sob a ótica da revista, evidenciando um discurso de instabilidade política, com a apresentação das negativas condições econômicas, bem como o alto índice de inflação e desemprego, que ao seu ver poderia ser solucionado com a saída urgente da presidenta eleita. Ademais, o autor faz uso da Constituição Federal para fundamentar a legitimidade desse evento, apresentando os solicitantes do processo de impedimento com seus respectivos currículos, mostrando que entendem do que estão falando e que são especialistas na área jurídica.

Por fim, Pereira (2015) apresenta as discussões entre a presidenta Dilma e o presidente da Câmara Federal, Eduardo Cunha, ambos "trocando farpas" e se acusando acerca dos problemas que levaram o país ao suposto caos econômico. Nessa perspectiva, e em consonância com a categoria de análise apresentada nos fundamentos teóricos e detalhada na nossa metodologia, aprofundamos a discussão acerca do significado acional, focalizando principalmente nas marcas intertextuais que produzem uma discursividade no tocante ao evento impeachment, o qual nos posicionamos, como analistas do discurso, em denominar Golpe de 2016.

O Brasil passará a conviver com a sobreposição de cenários ainda mais complexos. Na economia, estão dadas as condições para o que pode ser a crise mais profunda de todos os tempos (PEREIRA, 2015).

$\mathrm{Na}$ expressão em destaque, como no decorrer de todo o texto, são perceptíveis as marcas de intertextualidade, tendo em vista a afirmação categórica do autor em dizer que este momento político necessita do impeachment, em vista de que seus argumentos são pautados pelo que ele denomina como 
sendo a maior crise econômica de todos os tempos, entendendo a intertextualidade implícita, nesta afirmação, que para existir necessita de um prévio conhecimento sobre as crises econômicas ao longo da história do país.

Para tanto, o autor não deixa claro quais são os motivos que o levaram a considerar o atual momento como sendo a crise mais profunda que o país vivencia.

$\mathrm{Na}$ defensiva, as indústrias se recolhem ao mínimo de atividade produtiva. $\mathrm{O}$ comércio prevê o pior Natal em décadas (PEREIRA, 2015).

Outra marca de intertextualidade são as vozes atribuídas às indústrias, de maneira genérica, quando não estão conseguindo produzir de forma efetiva, haja vista uma crise econômica ocasionada pelo Governo Federal, bem como a previsão do pior Natal de todas as décadas, atribuída à voz do comercio, também de maneira genérica, sem especificar quem realmente marca essa fala.

Pela Constituição, cabe ao comandante da Câmara dos Deputados aceitar ou negar os pedidos de impedimento apresentados contra o presidente da República. O deputado Eduardo Cunha deu seguimento na semana passada ao recurso formulado pelo jurista Hélio Bicudo, pelo ex-ministro da Justiça Miguel Reale Júnior e pela advogada Janaina Paschoal (PEREIRA, 2015).

O autor usar outros recursos intertextuais quando se apoia na Constituição de 1988, tendo em vista o artigo 85 e a Lei 1079/1950 que legitimam os processos de impedimento de presidentes, atribuindo ao presidente da Câmara Federal a responsabilidade em aceitar ou negar a continuação e efetivação do processo.

Percebemos a responsabilidade que o presidente da Câmara Federal, que nesse período era Eduardo Cunha, tem quanto aos desdobramentos desse processo. Ele era do partido aliado à presidenta, tendo como vice-presidente Michel
Temer, sendo um dos mais importantes políticos de sua sigla partidária.

Eles alegam que Dilma cometeu crime de responsabilidade ao praticar as chamadas pedaladas fiscais e gastar recursos sem a devida autorização prévia do Congresso (PEREIRA, 2015).

Dando continuidade, o autor usa recursos anafóricos que fazem referência aos nomes citados anteriormente, Hélio Bicudo, Miguel Reales Júnior e Janaina Paschoal, juristas que protocolaram o pedido de impedimento da então presidenta Dilma.

Um exemplo do que está por vir no terreno das manipulações pôde ser visto logo nos primeiros minutos após Eduardo Cunha anunciar a admissão do processo de impeachment (PEREIRA, 2015).

Outro momento em que o autor utiliza a intertextualidade é para marca, através do discurso indireto, o posicionamento desses atores sociais frente ao processo de impedimento.

O deputado foi chamado de corrupto e chantagista e acusado de agir motivado pelo nada nobre instinto de vingança. Esses argumentos encontram amplo respaldo nos fatos, mas são usados de maneira ardilosa para tentar confundir os brasileiros (PEREIRA, 2015).

Cunha reagiu, chamando a petista de "mentirosa" por ter declarado que jamais ofereceu a ele um acordo de proteção mútua. Em linha com a cartilha dos marqueteiros oficiais, a presidente quer restringir o caso a um duelo de biografias da santa da moralidade com o tinhoso do fisiologismo (PEREIRA, 2015).

Os agentes econômicos concordam com esse sentido de urgência. O simples início da tramitação do caso fez a cotação do dólar cair e a Bolsa subir, puxada pela valorização das ações de empresas controladas pelo governo (PEREIRA, 2015).

Outra marca intertextual percebida pelo contexto trata-se de Dilma Rousseff quando acusa o deputado Eduardo Cunha de ser chantagista e corrupto, bem como as marcas indiretas de intertextualidade atribuídas ao discurso do próprio deputado, de maneira generalizada como os agentes 
econômicos. Quem são esses agentes? Por que são apresentados de forma genérica?

Vale ressaltar que durante todo o percurso de arquitetura do Golpe de 2016, muito se relatava que a então presidenta não cedia às chantagens da base aliada, por isso estava sendo impedida de dar continuidade ao seu plano de governo, uma vez que os cenários são colocados como necessários aos gestores nas mais diversas esferas.

A afirmação baseada na cotação do dólar e na bolsa dá maior credibilidade argumentativa ao autor que se utiliza desses artifícios intertextuais para solidificar sua tese acerca da legitimidade e necessidade desse processo de impedimento.

Já, no segundo artigo analisado, Pereira e Bronzatto (2016) apresentam, logo no título do artigo, uma referência intertextual à voz de Franklin Martins quando remete que está se encerrando o ciclo do PT no poder. Eles comparam o partido e seu projeto político como sendo uma tentativa frustrada de se perpetuar nos próximos 20 anos no governo, conforme foi o PSDB, colocando os partidos políticos como sendo equivalentes em seus propósitos governamentais. Nesse sentido, os autores traçam um mapa mental sobre o que eles denominam como sendo a perpetuação petista no poder, entendendo que a classe média estava crescendo e que, por conta disso, deveria continuar votando nesse projeto político, caso não tivesse sido "drasticamente abreviado".

Utilizando-se de vozes diversas, sejam de políticos, de autoridades e de nomes dos três poderes, os autores traçam, neste artigo de opinião, a justificativa de atestar, como eles mesmo anunciam, “o óbito do ambicioso plano de hegemonia política do PT", tendo em vista que o partido, em meio a esse cenário, resumiu-se em corrupção gigantesca que impulsionou milhares de manifestantes às ruas clamando por justiça, que para eles seria finalizado com o impeachment.

Por fim, a revista, através de seus jornalistas, coloca-se em defesa do processo de impedimento da presidenta Dilma Rousseff e expressa veementemente seu posicionamento político ao atribuir toda corrupção que estava sendo evidenciada pela mídia como sendo exclusivamente do PT, e tendo o ex-presidente Lula como o "chefe do esquema de corrupção", anunciada há tempo pela revista. As vozes que são expressas e muito bem articuladas pelos autores, no desenvolvimento do artigo em análise, mostram uma boa seleção de argumentos que vão dando sustentação à tese do texto, ou seja, a justificativa necessária para a opinião pública quanto a necessidade do processo de impedimento da então presidenta Dilma Rousseff, uma vez que esta praticou crimes em parceria com a organização criminosa denominada Partido dos Trabalhadores.

(09) Impeachment põe fim ao ciclo do P'T no poder (PEREIRA; BRONZATTO, 2016).

No excerto acima, os autores fazem referência direta à fala do então Ministro das Comunicações Sociais, Franklin Martins, que diz que o governo petista iniciou um: "ciclo virtuoso de crescimento com inclusão social", expressão esta que também é de conhecimento geral sobre o dito popular "ciclo vicioso", fazendo referência reversa ao tratar do projeto governamental da então presidenta.

Porém, o pensamento diferente do senso comum acerca do ciclo virtuoso expresso pelo então ministro das comunicações é retomado, em sua originalidade, pelos autores, ao expressarem o fim do ciclo do PT, tendo em vista que todos os argumentos expressos no decorrer do artigo vão embasando uma ideia voltada para vícios não 
benéficos ao desenvolvimento econômico, social e político do país.

(10) A longo prazo, comandar o país por pelo menos vinte anos, justamente a meta traçada anteriormente, e não alcançada, pelo PSDB. Entre os aliados de Lula e Dilma, havia até quem trabalhasse com horizontes mais ambiciosos. O ministro de Comunicação Social, Franklin Martins, dizia que "o ciclo virtuoso de crescimento com inclusão social" renderia frutos duradouros. Festejada na propaganda oficial, a nova classe média, dínamo do crescimento de 7,5\% em 2010, despejaria votos nos petistas por anos a fio, talvez décadas: oito anos de Lula, oito anos de Dilma, a volta de Lula, a consagração de Fernando Hadda $\mathrm{O}$ roteiro estava traçado. Nele, eternizar-se no poder não era mera figura de linguagem (PEREIRA; BRONZATTO, 2016).

O fragmento acima traz várias marcas de intertextualidade, algumas utilizadas de forma positiva para dar mais credibilidade à tese dos jornalistas, outras usadas de forma superficial, principalmente quando podem dar algum crédito aos governos petistas, alvo principal de ataque por parte da revista Veja e da mídia hegemônica, como um todo.

A primeira expressão em destaque "pelo menos vinte anos" é retomada na articulação textual logo em seguida, quando fazem referência ao período em que o PSDB (quase) ficou em atividade à frente do executivo nacional. Porém, esta informação não é bem utilizada, pois não aprofunda com dados concretos e informações mais detalhadas sobre o projeto psdbista de governo, diferentemente quando se utiliza para atacar o PT.

A expressão "quem trabalhasse com horizontes mais ambiciosos", evidencia mais à frente, o "quem?" que seria o então ministro das comunicações, sendo colocando como aquele que é ambicioso e que deseja se perpetuar no poder junto a hegemonia petista.

Os autores falam sobre um possível crescimento de “7,5 \%, em 2010", porém não citam fontes que confirmem essa afirmação, muito menos aprofundam como ocorreu tal crescimento e por que, realmente, cresceu, tornando-se assim dissonante da ideia central do impedimento. Como um país que está crescendo com índices recordes pode interromper esta proposta política?

Por fim, o excerto traz a possível consagração de Fernando Haddad, não bem elaborada, pois os autores não detalham como isso seria possível, deixando subentendido essa ideia, como se a população já soubesse o desfecho da história.

(11) Por 61 votos a 20, os senadores aprovaram o impeachment de Dilma e encerraram um período de treze anos de governo do PT, atendendo ao clamor de milhões de brasileiros que foram às ruas em manifestações históricas (PEREIRA; BRONZATTO, 2016).

Os autores, no destaque do excerto (11), evidenciam que milhares de brasileiros estavam nas ruas clamando pelo impedimento da então presidenta, porém não há um aprofundamento sobre essas manifestações, como elas ocorreram, como começaram e sua ideia inicial. Essa intertextualidade remete as manifestações que ficam implícitas no texto, pois nesse período havia ondas de manifestações sobre as mais variadas pautas.

(12) Um plano que, desde a chegada do partido
ao Planalto, estava assentado num pecado
original, que não foi inventado pelo PT, não foi
implantado pelo PT, mas foi executado com
rigor e método nunca antes vistos neste país:
a corrupção da classe política com recursos
públicos (PEREIRA; BRONZATTO, 2016).

Dando sequência aos argumentos utilizados pelos autores para sustentar a tese que objetivava sustentar a postura favorável ao processo de impedimento da então presidenta, como sendo necessário, nesse cenário, para acabar com a corrupção, o destaque mostra o processo de demonização do projeto político dos governos do PT, uma vez que faz referência ao pecado original, 
a primeira forma de mal existente na tradição cristã, como também utilizado para remeter aos partidos anteriores que ocupavam o executivo e legislativo e também estavam ligados a corrupção, porém atenuadas diante do que pode ser um caso de maior magnitude comparado ao PT.

Se pensarmos nessa perspectiva, podemos destacar como pecado original, antes do PT chegar ao poder, a corrupção ativa e lavagem de dinheiro apontados na lista Furnas ${ }^{2}$, nos anos 2000, envolvendo emprestas estatais de companhias elétricas que desviavam dinheiro para abastecer campanhas de políticos ligados, em sua maioria, ao PSDB e ao PFL (atual DEM), grupos políticos que governam o país, na época. Nesse sentido, podemos destacar ainda a própria "privataria" e o mensalão tucano.

A segunda expressão destacada no excerto (12) "nunca antes visto" faz referência ao bordão utilizado pelo ex-presidente Lula quando, em seu discurso, inaugurava alguma obra ou assinava algum projeto que fosse pioneiro e que nunca se havia pensado nada igual a favor da população brasileira.

(13) Em 2005, VEJA mostrou um funcionário dos Correios recebendo propina. A estatal era fatiada entre PT, PMDB e PTB. Cada partido controlava uma diretoria, recolhendo dinheiro sujo em sua área. A verba subornava parlamentares no Congresso. Era o mensalão (PEREIRA; BRONZATTO, 2016).

Por fim, além de diversos recursos de biperlinks no decorrer do texto, que colaboram para contribuir com mais detalhes na sustentação das informações e dos argumentos apresentados pelos autores, eles utilizam-se de outro escândalo anterior, denominado como mensalão petista, porém sem aprofundar o que foi verdadeiramente esse primeiro escândalo político que não passou de uma tentativa de fazer, muito antes, o que se

2 Disponível em: <https://www.cartacapital.com.br/ politica/o-mensalao-tucano-e-a-lista-de-furnas-9434/> Acesso em: 23 de nov. 2019. fez agora, derrubar um governo legítimo e eleito democraticamente, como afirma Souza (2016)

\section{CONSIDERAÇÕES FINAIS}

A intertextualidade analisada aqui, nos direcionam para a reflexão acerca de uma efetiva compreensão da forma de modalização discursiva para a legitimação do Golpe de 2016, uma vez que a grande mídia hegemônica brasileira utilizase de mecanismos intertextuais, ou seja, de vozes legitimadas para traçar um perfil incriminatório contra a proposta política dos governos petistas, culminando no impedimento da presidenta eleita democraticamente.

A grande mídia, tendo em vista o pensamento de Souza (2016) sempre esteve como aliada das grandes corporações brasileiras, fomentando em rede aberta, um discurso de ódio ao Partido dos Trabalhadores e aos grupos minoritários ligadas à esquerda, fomentando uma fala padrão de que tais grupos formam a pior organização criminosa política que o país já teve.

Em suma, esperamos que a discussão empreendida nesta dissertação possa despertar para a reflexão efetiva desse evento político, construído e articulado, principalmente com o apoio da mídia hegemônica, haja vista que todo o cenário social que se vivencia na contemporaneidade está intrinsecamente ligado ao golpe como um possível desdobramento, bem como uma atenção especial aos mecanismos inerentes ao uso efetivo da linguagem que colaboram para a construção das relações sociais.

\section{REFERÊNCIAS}

BOFF, O. M. B.; KÖCHE, V.S.; MARINELLO, A. F. O gênero textual artigo de opinião: um meio de interação. Revista Virtual de Estudos das Linguagem - ReVEL, vol. 7, n. 13, 2009. Disponível 
em: <http://www.revel.inf.br/files/artigos/ revel_13_o_genero_textual_artigo_de_opiniao. pdf $>$ acesso em: 23 nov. 2019.

BRANDÃO, H. H. N. Introdução à Análise do Discurso. 1 ed. Campinas: Editora da Unicamp, 1986.

BRAZ, M.. O golpe nas ilusões democráticas e a ascensão do conservadorismo reacionário. Revista Serviço Social e Sociedade. São Paulo, n. 128. p. 85-103. jan/abr. 2017. Disponível em < http:// www.scielo.br/pdf/ss soc/n128/0101-6628sssoc-128-0085.pdf> Acesso em 23 nov. 2019

CASTILHO, M. L. O discurso de estudantes de licenciatura e negociação de identidades: uma abordagem crítico-discursiva.308f.Tese(Doutorado em Linguística) Universidade de Brasilia, Instituto de Letras, Departamento de Linguística, Português e Línguas Clássicas, Programa de Pós-Graduação em Linguística, Brasília, 2013.

CHOULIARAKI， L.; FAIRCLOUGH， N. Discourse in Late Modernity. Edinburg: Edinburg University Press, 1999.

COSTA, N. B.(org.). Práticas Discursivas: exercícios analíticos. Campinas: Pontes Editores, 2005.

FAIRCLOUGH, N. Analysing Discourse: textual analysis for social research. London: Routledge, 2003.

FAIRCLOUGH, N. Discurso e Mudança Social. (Coordenação da trad.) Izabel Magalhães. Brasília: UNB, 2001.

FONSECA, F. Mídia, poder e democracia: teorias e práxis dos meios de comunicação. Revista Brasileira de Ciência Política. Brasília, jun - dez de 2011, p. 41-69. Disponível em < http://www.scielo.br/ $\mathrm{pdf} / \mathrm{rbcpol} / \mathrm{n} 6 / \mathrm{n} 6 \mathrm{a03} \cdot \mathrm{pdf}>$. Acesso em: $13 \mathrm{de}$ maio de 2019.

FONSECA, P.C.D.; CUNHA, A.M.;BICHARA, J.S. OBrasil na era Lula: retorno ao desenvolvimentismo. Revista Nova Economia. Belo Horizonte, n. 23, maio-agosto de 2013, p. 403-428. Disponível em: < http://www.scielo.br/scielo.php?script=sci_artt
ext\&pid=S0103-63512013000200006 $>$ Acesso em 23 nov. 2019.

GUERRA, A. [et al]. Brasil 2016: recessão e golpe. São Paulo: Fundação Perseu Abramo, 2017.

ORLANDI, E. P. Análise de discurso: princípios \& procedimentos. 10 ed. Campinas, SP: Pontes, 2012.

PÊCHEUX, M. Semântica e discurso. Uma crítica à afirmação do óbvio. Tradução Eni Pulcinelli Orlandi [et al.], Campinas: Editora da Unicamp, 1997a.

PEZATTI, E. G. Ordenação de constituintes em sentenças declarativas do português brasileiro. Revista de Estudos Linguísticos: Veredas, UFJF: Juiz de Fora, 2011. v. 15, n. 1, p. 206-221.Disponível em: < http://www.ufff.br/revistaveredas/ files/2011/05/ARTIGO-151.pdf > acesso em: 23 nov. 2019.

PINTO, R. B. W. S. . A heterogeneidade constitutiva do ethos no editorial português. Revista Calidoscópio, UNISINOS: São Leopoldo, v. 2, n. 2, p. 25-32, jul/dez. 2004. Disponível em: <http:// revistas.unisinos.br/index.php/calidoscopio/ article/view/6447> Acesso em: 23 nov. 2019.

RAMALHO, V. Diálogos teórico-metodológicos: análise de discurso crítica e realismo crítico. Cadernos de Linguagem e Sociedade. v. 8, p. 78104, 2006/7. Disponível em: < http://periodicos. unb.br/index.php/les/article/view/1247> Acesso em: 10 fev. 2018.

RESENDE, V de M; RAMALHO, V. Análise de Discurso Crítica, Modelo Tridimensional à articulação prática: Implicações teóricometodológica. Linguagem em (Dis)curso - LemD Tubarão, v. 5, n. 1, p. 185 - 207, jul./dez.. 2004. Disponível em: <http://www.portaldeperiodicos. unisul.br/index.php/Linguagem_Discurso/ article/view/307/323> Acesso em: 27 jul. 2018.

RESENDE, V de M; RAMALHO, V. Análise de Discurso Crítica. São Paulo: Contexto, 2017.

RESENDE, V. de M. Análise de discurso crítica e Realismo Crítico: implicações interdisciplinares. 
Campinas: Pontes, 2009.

ROVAI, R. Golpe 16. São Paulo: Edições Fórum;

Publisher Brasil, 2016.

SOUZA, J. A radiografia do golpe: entenda como e por que você foi enganado. Rio de Janeiro: Leya, 2016.

TRIVIÑOS, A. N. S. Três enfoques na pesquisa em ciências sociais: o positivismo, a fenomenologia e o marxismo. In: TRIVIÑOS, Augusto Nibaldo Silva. Introdução à pesquisa em ciências sociais. São Paulo: Atlas, 1987. p. 31-79.

VAN DIJK, T. Discurso e poder. São Paulo: Contexto, 2010.

Submissão: janeiro de 2020.

Aceite: setembro de 2020. 